\title{
Simulations of the Atmospheric Response to South Atlantic Sea Surface Temperature Anomalies
}

\author{
ANDREW W. ROBERTSON \\ International Research Institute for Climate Prediction, Palisades, New York \\ John D. FARrara AND CARlos R. Mechoso \\ Department of Atmospheric Sciences, University of California, Los Angeles, Los Angeles, California
}

(Manuscript received 16 April 2002, in final form 28 January 2003)

\begin{abstract}
The sensitivity of the atmospheric circulation to sea surface temperature (SST) anomalies in the tropical and subtropical South Atlantic Ocean is studied by means of simulations with an atmospheric general circulation model (GCM). Two types of prescribed SST anomalies are used, motivated by previous analyses of data. The first occurs during austral summers in association with a strengthening of the South Atlantic convergence zone (SACZ) and consists of cold SST anomalies over the subtropical South Atlantic. The second is the leading seasonally varying empirical orthogonal function of SST, consisting of warm basin-scale anomalies with maximum amplitude in the subtropics during January-March and at the equator in June. An ensemble of about 10 seasonal simulations is made using each type of anomaly, focusing on the January-March period in the first case and the January-June seasonal evolution in the second.

During January-March both experiments yield a statistically significant baroclinic response over the subtropical Atlantic with dipolar SACZ-like anomalies. Some evidence of positive feedback is found. The response is shown to be fairly similar in pattern as well as amplitude to the linear regression of observed interannual low-level wind anomalies with subtropical SST anomalies. However, in the first experiment with cold SST anomalies, the simulated response contrasts with the leading interannual mode of observed SACZ variability.

Warm basin-scale anomalies are found to have their largest impact during boreal summer, with a strong statistically significant equatorial baroclinic response and positive rainfall anomalies over the equatorial ocean. The latter do not extend appreciably into the adjacent continents, although there are significant positive rainfall anomalies over the Sahel in April-June and negative anomalies over the western Indian Ocean. In the upper troposphere, a statistically significant wave train extends southwestward to southern South America and northeastward to Europe in April-June, while there is some linkage between the tropically and subtropically forced responses during January-March.
\end{abstract}

\section{Introduction}

The dynamics of tropical Atlantic variability has often been described in terms of two modes: an equatorial mode with dynamics similar to those of the El NiñoSouthern Oscillation (ENSO), but highly damped (Zebiak 1993; Tseng and Mechoso 2000), and a meridional mode with centers over the tropical North and South Atlantic (Chang et al. 1997; Dommenget and Latif 2000). Several studies have addressed tropical North Atlantic variability, which directly impacts the intertropical convergence zone (ITCZ) and is strongly influenced by ENSO in boreal spring (Enfield and Mayer

Corresponding author address: Dr. Andrew W. Robertson, International Research Institute for Climate Prediction, P.O. Box 1000, Palisades, NY 10964.

E-mail: awr@iri.columbia.edu
1997; Saravanan and Chang 2000), and by the North Atlantic Oscillation (NAO; Namias 1972). Fewer studies have addressed variability over the South Atlantic.

Interannual variations in the strength and position of the subtropical anticyclone and the South Atlantic convergence zone (SACZ) are accompanied by SST anomalies over the subtropical South Atlantic (Venegas et al. 1997; Robertson and Mechoso 2000; Barros et al. 2000). Several observational studies have concluded that these anomalies are largely due to local thermodynamic forcing by the atmosphere (Kalnay et al. 1986; Venegas et al. 1997; Sterl and Hazeleger 2003, manuscript submitted to J. Climate). SACZ-related SST anomalies, however, extend beyond the atmospheric feature. Their structure is dipolar with a nodal line running approximately along the confluence between the Brazil and Malvinas Currents off southeastern South America, 
which suggests a potential role of oceanic advection in the establishment of this feature. To our knowledge, no published studies have addressed the sensitivity of the atmosphere to an idealized SST anomaly of this form using an atmospheric general circulation model (GCM).

Due to asymmetries in continental geometry, the "meteorological equator," defined by the meridional position of the ITCZ lies generally north of the equator. The eastern equatorial cold tongue-where El Niñolike atmosphere-ocean interactions are believed to operate-is open to the South Atlantic but isolated from the North Atlantic by West Africa. Thus, the subtropical anticyclone over the South Atlantic directly influences the equatorial eastern Atlantic through the southeast (SE) trade winds. The presence of the summer monsoonal circulation over South America contributes to the potential importance of the South Atlantic in tropical Atlantic climate variability (Horel et al. 1989). The Amazonian convergence zone that develops in austral summer and extends southeastward to form the SACZ is intimately related to the strength and position of the subtropical anticyclone over the South Atlantic. The relationship is established both through the compensation of ascent and descent in thermodynamically direct overturning cells (Gandu and Silva Dias 1998), as well as through the southward advection of moist static energy into the subtropical convergence zone over South America on the western flank of the subtropical anticyclone (Kodama 1992, 1993). The narrowness in longitude of the tropical Atlantic Ocean compared to the Pacific makes the adjacent land-based convection zones of potential importance to the atmospheric circulation over the ocean and, in particular, to the extensions of the ITCZ into equatorial Africa and northeast (NE) Brazil.

Sea surface temperature anomalies over the South Atlantic are highly seasonal. Over the subtropics, they are strongest during austral summer when the SACZ and South American monsoon system reach their peak intensities. Starting in May-June, the dominant SST variability over the South Atlantic is associated with that of the equatorial cold tongue complex, with subtropical variability greatly diminished.

This paper presents simulations with an atmospheric general circulation model designed to investigate the sensitivity of the atmosphere to South Atlantic SST anomalies during the calendar half-year January-June, focusing on the subtropical SST anomalies that are observed to accompany changes in the intensity of the SACZ and the subtropical anticyclone in JanuaryMarch, and the increasingly strong equatorial anomalies that develop by June. Section 2 describes the GCM experiments. A specifically SACZ-related SST anomaly experiment is presented in section 3. In section 4, we describe the GCM's response to the leading seasonally varying empirical mode of interannual variability from January-June. Section 5 presents a discussion and conclusions.

\section{Model and simulations}

We use the University of California, Los Angeles (UCLA) AGCM, which includes advanced parameterizations of the major physical processes in the atmosphere. The parameterization of cumulus convection is a version of the Arakawa-Schubert scheme (Arakawa and Schubert 1974) in which the cloud work function quasi-equilibrium assumption is relaxed by predicting the cloud-scale kinetic energy (Randall and Pan 1993). Planetary boundary layer processes are parameterized using the mixed-layer approach of Suarez et al. (1983) as recently revised by $\mathrm{Li}$ et al. (1999); these modifications result in much improved surface latent heat fluxes and maritime stratocumulus cloud incidence. The parameterization of radiative processes is from Harshvardhan et al. (1987, 1989). A more detailed description of the model can be found in Mechoso et al. (2000) and online at http://www.atmos.ucla.edu/esm/agcmdir.

The work is performed with the high-resolution $2^{\circ}$ latitude $\times 2.5^{\circ}$ longitude, 29-layer configuration of the model version 6.98 , which is identical to that used by Farrara et al. (2000) in their study of the atmospheric response to the 1997/98 El Niño. The integrations cover the period 1 November-31 March (section 3) and 1 November-30 September (section 4). Two 10-member seasonal control ensembles were performed using the Global Sea Ice and Sea Surface Temperature dataset (GISST) climatological SSTs 1960-90 (Rayner et al. 1995), the first covering the period 1 November-31 March, and a second ensemble of longer runs for 1 November-30 September. Two additional ensembles were performed, each with different distributions of SST anomalies added to the climatological fields, as described in sections 3 and 4 below. The initial conditions were obtained by adding small random perturbations to the model's prognostic variables corresponding to an atmospheric state in northern fall (1 October).

\section{Subtropical cold anomaly}

Figure 1 shows the leading empirical orthogonal function (EOF) of interannual atmospheric 200-hPa wind variability over subtropical South America in summer [January-February-March (JFM)], as constructed from the National Centers for Environmental Prediction-National Center for Atmospheric Research (NCEP-NCAR) reanalysis data (Kalnay et al. 1996) by Robertson and Mechoso (2000). Figure 1a consists of regression maps with $850-\mathrm{hPa}$ winds and $500-\mathrm{hPa}$ omega vertical velocity, and shows a northward intensified SACZ accompanied by anomalous descent to the southwest, and by a cyclonic wind field such that anomalous ascent coincides with anomalous northwesterly winds and vice versa. Thus, tropical moisture is channeled into the SACZ, while the opposite occurs to the southwest. In this case the low-level southward jet east of the Andes (Virji 1981) is weakened, resulting in less advection of 
a) UV-850/OMG-500

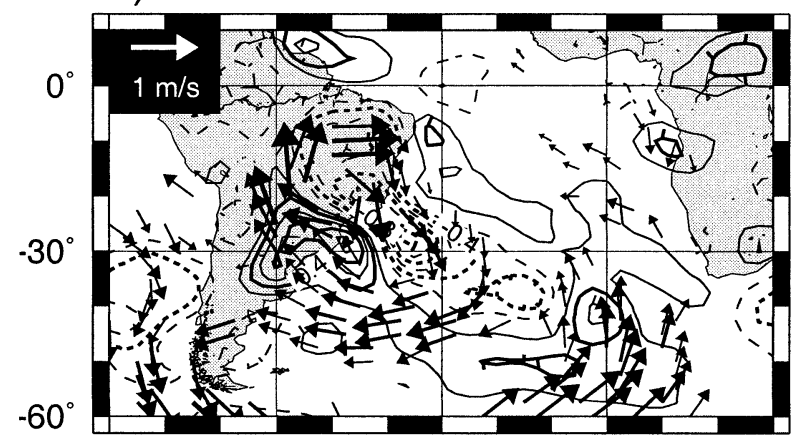

b) SST

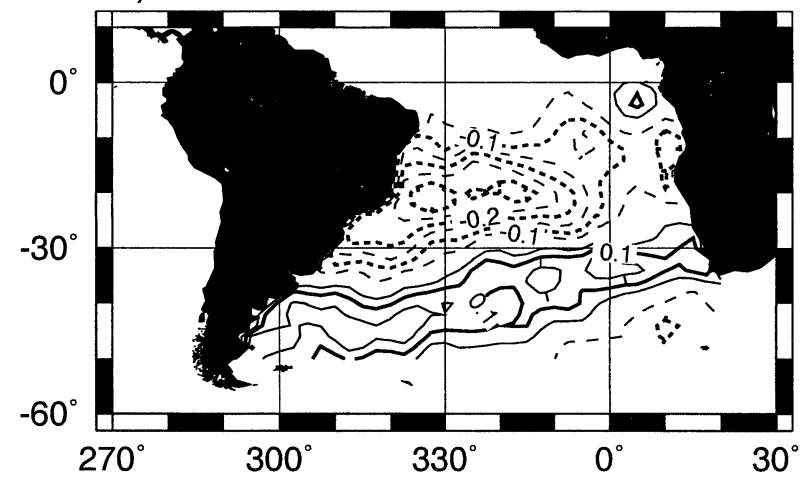

FIG. 1. Regression maps of the leading PC of 200-hPa JFM-averaged winds 1958-97 over southern South America from the NCEPNCAR reanalysis. (a) 850-hPa winds and 500-hPa omega, (b) GISST SST. In (a), only vectors whose correlations with the PC are significant at the $95 \%$ level are plotted, with the number of degrees of freedom of the two-sided Student's $t$ test estimated at each grid point from the decorrelation times of the PC and winds time series (Davis 1976). See Robertson and Mechoso (2000) for further details. Contour intervals are (a) $0.2 \times 10^{-2} \mathrm{~Pa} \mathrm{~s}^{-1}$, and (b) $0.05 \mathrm{~K}$, with the zero contour omitted. Amplitudes correspond to a one std dev excursion of the PC.

moisture-rich air into SE South America. Figure 1b shows the analogous regression map of GISST SST, with broadscale subtropical cold anomalies and weak warm anomalies to the south. Correlations with remote SSTs are not statistically significant (Robertson and Mechoso 2000).

The SST anomaly distribution in Fig. 1b was multiplied by a factor of 3 to enhance the signal-to-noise ratio, yielding maximum cold anomalies of about $1 \mathrm{~K}$, and prescribed as a fixed SST anomaly on top of the monthly GISST climatology in the region $50^{\circ} \mathrm{S}-0^{\circ}$, $70^{\circ} \mathrm{W}-20^{\circ} \mathrm{E}$. An ensemble of nine November-March seasonal simulations was then made. While the prescribed anomaly's amplitude corresponds to three standard deviations of the observed interannual distribution, a 1-K anomaly can be considered a simple order-ofmagnitude estimate for those observed.

Figure 2 shows the JFM-average ensemble mean response of the simulated atmosphere to the prescribed SST anomaly. The anomalous wind vectors are only plotted where at least one component is statistically significant at the $95 \%$ level, with the $95 \%$ significant areas of the scalar fields shaded in Figs. 2c-e. Statistical significance was estimated using a conventional two-sided two-sample Student's $t$ test. Assuming that population variances of each ensemble are equal, there is 1 degree of freedom per simulation (minus 2), yielding 27 degrees of freedom in all (using both 10-member control runs to compare against).

The GCM's response consists of an anomalous anticyclonic circulation at low levels, which is centered at about $30^{\circ} \mathrm{S}$ over the western Atlantic and penetrates well into the continent north of $30^{\circ} \mathrm{S}$. The response is baroclinic with an anomalous cyclonic circulation aloft. The pattern is characteristic of a Gill-type off-equatorial response to (negative) diabatic heating, though with some equatorward tilt with height. There is anomalous descent over the region of cold SST and compensating ascent to the southwest, typical of a Rossby wave. The cold SST anomaly induces a net heat flux anomaly into the ocean, tending to damp it, an anomalously cold lower troposphere (tending to be balanced by adiabatic warming through descent), and reduced rainfall. The cold anomaly extends into the continent while precipitation anomalies are largely confined to the ocean.

The anomalous low-level wind and midlevel omega fields exhibit a similar relationship to each other to that seen in the observed anomalies in Fig. 1. However, the simulated polarity of the vortex is opposite to the observed one. The response amplitudes are also weaker when the factor-of-3 enhancement of the prescribed SST anomaly is factored in. Thus, according to the simulation results the observed atmospheric anomalies in Fig. 1 are unlikely to forced by the accompanying SST anomaly, consistent with the conclusion of Kalnay et al. (1986).

\section{Evolving basin-scale pattern}

The usual next step in a GCM-based study would be to explore the linearity of the response by repeating the experiment in section 3 with the polarity of the SST anomaly reversed. However, since the form of the SST anomaly is highly specific to SACZ variations and due to the regional nature of the response pattern, we decided to consider a warm subtropical SST anomaly more typical of basin-scale observed SST variations. Figure 3 shows the leading EOF of seasonal-mean SST variability for the JFM and April-May-June (AMJ) seasons over the South Atlantic $\left(0^{\circ}-30^{\circ} \mathrm{S}\right)$. These were computed from the Reynolds and Smith (1994) extended SST dataset 1950-99, with the linear trend subtracted. In both seasons, the leading EOF has the same polarity covering the subtropics as well as the Tropics, with largest amplitudes in the subtropics near $20^{\circ} \mathrm{S}$ and in the equatorial cold tongue region. The dominant region of variability exhibits a pronounced seasonal shift from the subtropics in JFM to the equatorial cold tongue and the Gulf of 
a) UV-850

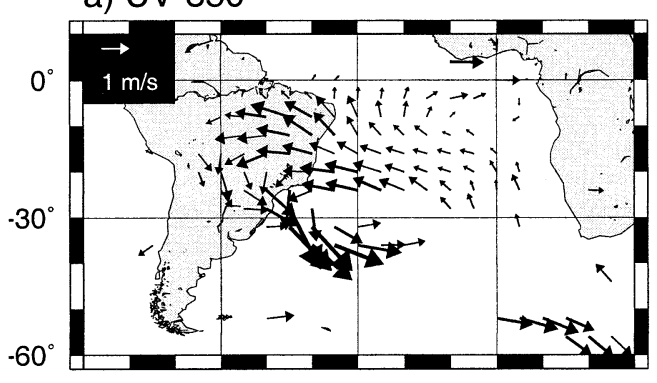

c) $\mathrm{T}-850$

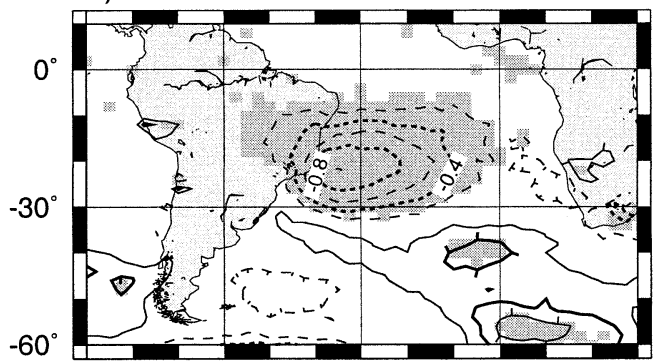

e) Net Sfc Heat Flux Up

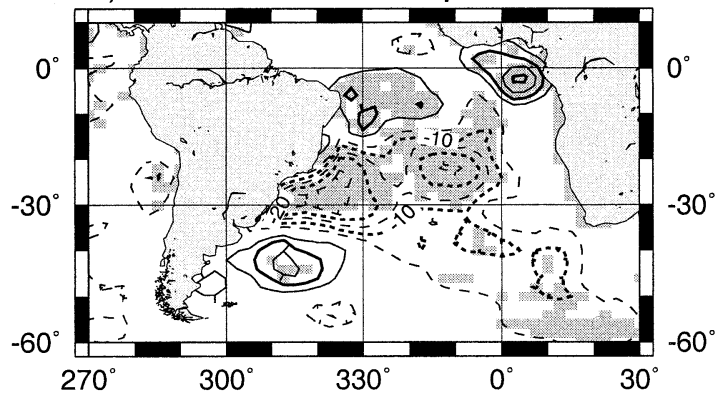

b) UV-200/OMG-500

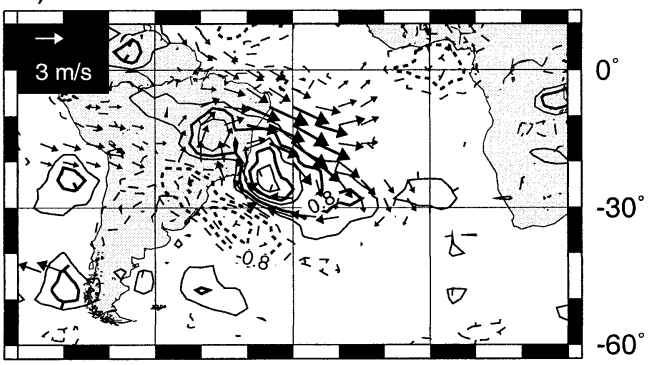

d) Precipitation

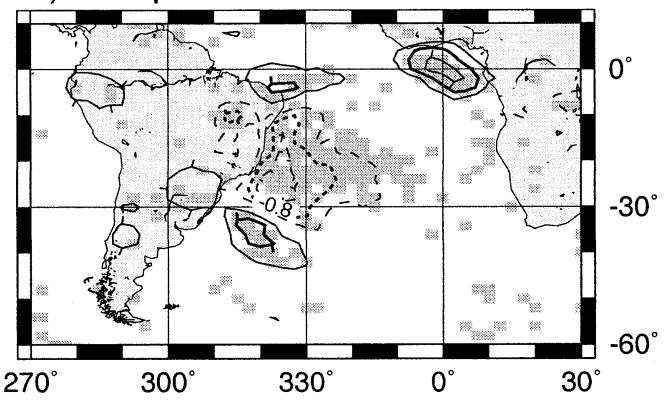

FIG. 2. JFM average GCM response to the SST anomaly pattern in Fig. 1b, with the latter multiplied by a factor of 3. (a) $850-\mathrm{hPa}$ winds, (b) $200-\mathrm{hPa}$ winds and $500-\mathrm{hPa}$ omega (contours), (c) 850-hPa temperature, (d) precipitation, and (e) net surface heat flux into the atmosphere. The response is defined as the difference between an ensemble of 9 anomaly simulations and 20 control simulations (see text). Shading indicates the $95 \%$ significance level, computed from a two-sided Student's $t$ test with 27 degrees of freedom, while in (a) and (b) only similarly significant vectors are plotted. Contour intervals are (b) $0.4 \times 10^{-2} \mathrm{~Pa} \mathrm{~s}^{-1}$, (c) $0.2 \mathrm{~K}$, (d) 0.4 $\mathrm{mm} \mathrm{day}^{-1}$, and (e) $5 \mathrm{~W} \mathrm{~m}^{-2}$; zero contours are omitted. Both (d) and (e) are spatially smoothed with a 9-pointaverage smoother.
Guinea in AMJ. The subtropical anomaly in JFM is again characterized by sharp meridional gradients near $30^{\circ} \mathrm{S}$ (cf. Fig. 1). In the second half of the calendar year (not shown), the AMJ pattern persists while weakening.

Figure 4 shows a sequence of SST patterns derived from the leading principal component (PC) of monthly SST variability $\left(0^{\circ}-30^{\circ} \mathrm{S}\right)$, with the mean seasonal cycle and linear trend subtracted. Each panel in Fig. 4 was derived by regressing the monthly PC onto the set of SST maps restricted to each respective calendar month. The amplitudes have been multiplied by a factor of 2 , yielding a positive anomaly maxima of about $1 \mathrm{~K}$. The resulting sequence captures the seasonal evolution of the broadscale warm pattern seen in Fig. 3, with a progression from sharpened meridional gradients at $30^{\circ} \mathrm{S}$ in the central basin peaking in February, toward a weakened equatorial cold tongue in June, characteristic of the Atlantic analog of El Niño (Zebiak 1993). The GISST dataset yields a similar sequence of maps, but the anomalies in the equatorial cold tongue region are less well defined. The SST anomaly distributions shown in Fig. 4 were used to force the GCM by adding them to the GISST climatology used in section 3 over the region $45^{\circ} \mathrm{S}-10^{\circ} \mathrm{N}, 70^{\circ} \mathrm{W}-20^{\circ} \mathrm{E}$, interpolating linearly in time. An ensemble of 10 November-September seasonal simulations was made. It was verified that the GISST and Reynolds climatologies for each calendar month are almost indistinguishable.

Figures 5 and 6 show the GCM's seasonally averaged ensemble-mean response in JFM and AMJ, respectively. The GCM's response can be compared with Fig. 7, which shows regression maps of "observed" NCEPNCAR $850-\mathrm{hPa}$ winds and 500-hPa omega, regressed against the SST PC used to construct the GCM forcing. During JFM, the subtropical response generally resembles that in section 3 (with the polarities reversed), shifted slightly eastward consistent with the corresponding eastward shift in the region of anomalous SST gradients. Thus, the response to subtropical South Atlantic SST anomalies is baroclinic and appears to be quite linear. 


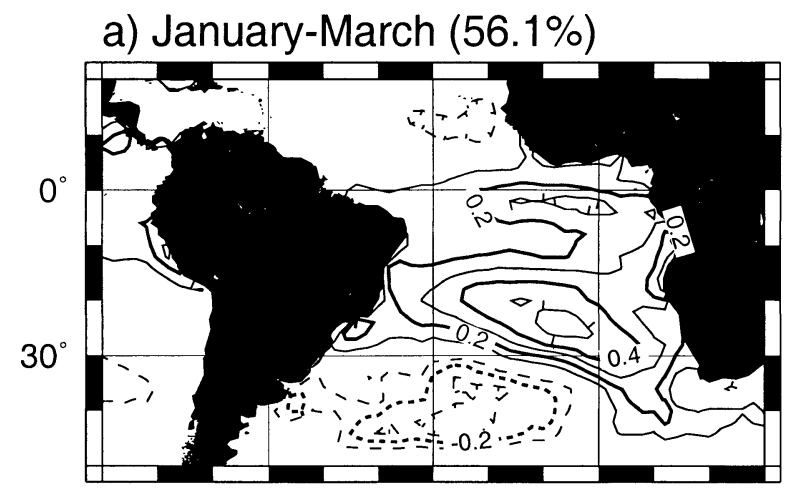

b) April-June (54.6\%)

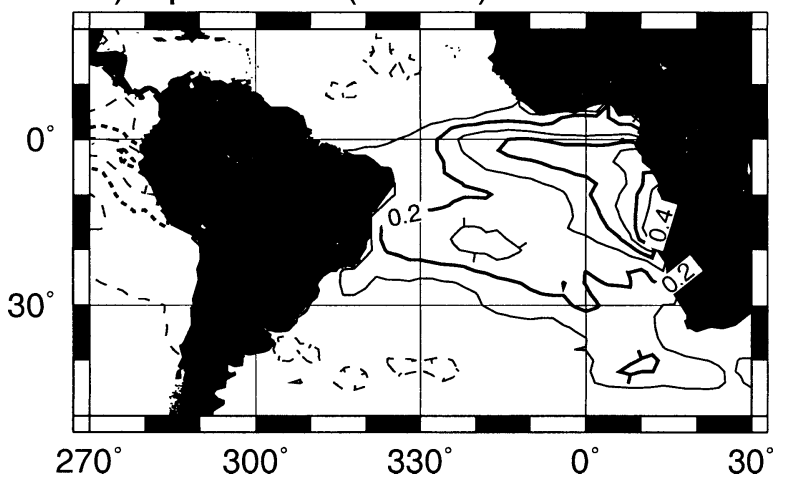

FIG. 3. The leading seasonal-mean EOF of the (linearly detrended) Reynolds SST dataset 1950-99, computed over the South Atlantic $0^{\circ}-30^{\circ} \mathrm{S}$ for (a) JFM, and (b) AMJ. Shown are regression maps with the respective PC. Contour interval is $0.1 \mathrm{~K}$, with the zero contour omitted.

There is a low-level cyclonic anomaly straddling the intensified SST gradient across $30^{\circ} \mathrm{S}$, with anomalous ascent (and precipitation) to the north and descent to the southwest (Fig. 5). The lower troposphere warms throughout the subtropics and Tropics.

We can gain insight into the linearity of the response by comparing the responses obtained with the SST anomalies in Figs. 1 and 4 and shown in Figs. 2 and 5, respectively. In both cases, low-level subtropical temperature amplitudes closely reflect those of the prescribed SST anomalies. The weaker response in the model's SACZ in Fig. 5 than in Fig. 2 is also consistent with this eastward shift of the anomalous SST forcing. On the other hand, over a large part of the western tropical Atlantic the net surface heat flux anomalies in both cases (Figs. $2 \mathrm{~d}$ and $5 \mathrm{~d}$ ) are directed into the ocean, which corresponds to a local damping of SST anomalies in the former case but to an amplification in the latter. Such contrasting behavior may be due to the different structure and amplitude of SST anomalies in the region for the two cases considered. In the first experiment (Fig. 2), the heat flux anomalies off the coast of SE Brazil are located close to the maximum of the prescribed negative SST anomaly (Fig. 1b) and naturally act to damp it. In the second experiment, the maximum of the pre- scribed warm SST anomaly is situated much farther east, with weak warm anomalies off the coast of Brazil. It appears that mechanical wind-induced changes in evaporation (associated with a weakening of the prevailing SE trade winds) can thus prevail here over a direct thermodynamic tendency toward damping, leading to a positive feedback.

Even during JFM the anomalous SST forcing in Fig. 4 extends to the equator, and the GCM response is very sensitive to this feature. The pattern resembles the classical baroclinic response to a deep atmospheric heat source at the equator, with strong low-level westerlies to the west of the heat source (associated with the positive equatorial precipitation anomaly). The low-level wind anomalies look similar to the pseudostress correlations with observed equatorial Atlantic SST anomalies, constructed by Zebiak (1993) and Tseng and Mechoso (2000). Surface heat flux anomalies are directed strongly into the atmosphere in the equatorial cold tongue region, tending to damp the warm anomaly there.

The model's circulation response pattern and amplitude in JFM are both fairly realistic in the subtropics, according to the regression pattern in Fig. 7a obtained from observational data. The equatorial wind response appears to be considerably overestimated. The realistic strength of the subtropical anomalies (taking into account the factor-of-2 amplification of the SST forcing) contrasts with weak response found in section 3. This may be due to the influence of the equatorially forced component, which is clearly linked to the subtropics at upper levels in Fig. 5b, and may tend to reinforce it.

In AMJ, the SST anomalies in Fig. 4 strengthen near the equator and weaken in the subtropics. The dynamical response simulated in that season becomes strongly confined to the equator with large rainfall anomalies throughout the tropical Atlantic accompanied by strong low-level westerly anomalies. The pattern of this tropical response is quite realistic (cf. Fig. 7b), and even the region of anomalous descent and southeasterly flow near $20^{\circ} \mathrm{S}$ is reflected in the observed pattern. However, the equatorial response is overestimated by a factor of $2-3$. The equatorial low-level wind anomalies in both the simulation and observation are more zonal than those found by Chang et al. (2000).

The simulated low-level temperature response closely mirrors the prescribed subtropical SST anomalies, and spreads eastward into most of Africa in AMJ. Net surface heat flux anomalies are only statistically significant in the equatorial cold tongue region, where they act to damp the SST anomaly. This is the typical situation over the equatorial Pacific during ENSO.

The global response during AMJ is shown in Fig. 8 in terms of 200-hPa wind, streamfunction, and precipitation. The precipitation anomalies in the tropical Atlantic sector are largely confined to ocean areas, with a remote negative anomaly over the western Indian Ocean. The only significant land feature is a band of weak positive anomalies over sub-Saharan Africa. An- 


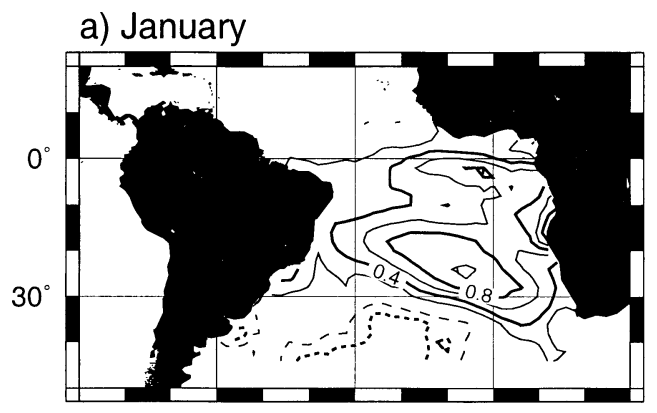

b) February

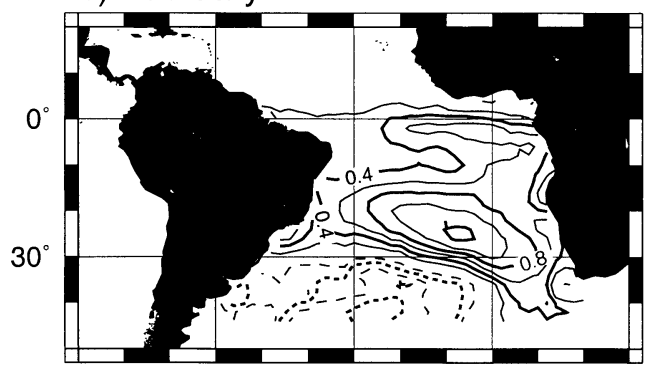

c) March

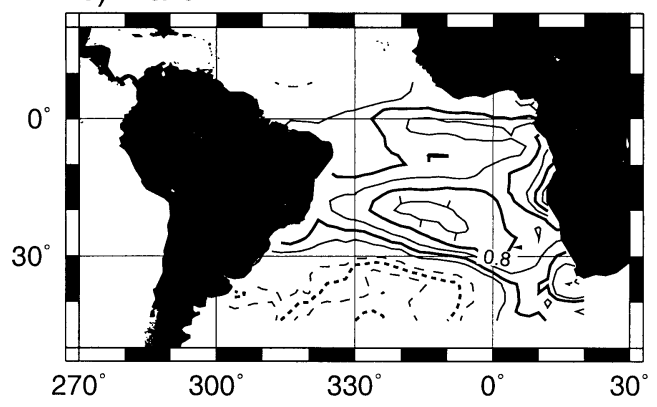

d) April

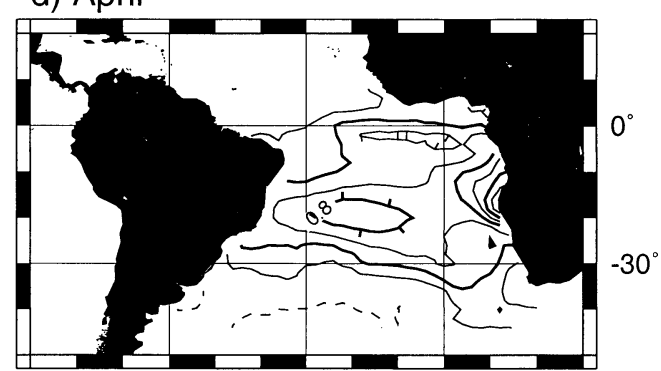

e) May

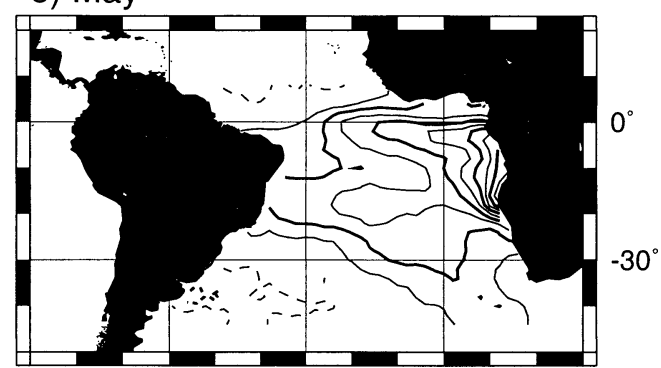

f) June

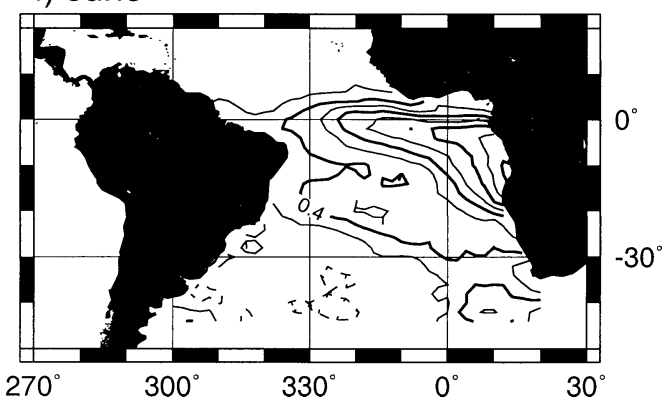

FIG. 4. Seasonal evolution of SST anomalies used to force the GCM in the experiment described in section 4. See text for details. Contour interval is $0.2 \mathrm{~K}$, with the zero contour omitted.

ticyclones develop at upper levels on either side of the equator, consistent with the linear Matsuno-Gill model. However, in contrast to the Pacific case during El Niño episodes, there is a noticeable meridional tilt with the anticyclone to the north being displaced eastward over Africa. The GCM results also indicate significant Rossby wave propagation northeastward into Europe and southwestward to southern South America. Thus, there is a marked meridional asymmetry not seen over the Pacific during ENSO.

\section{Discussion and conclusions}

Our goal in this paper is to illuminate outstanding aspects of ocean-atmosphere interactions over the South Atlantic by examining the response of an atmospheric GCM to oceanic anomalies prescribed in the Tropics and subtropics. In a previous study of atmospheric variability over South America, based on an EOF analysis of winds from observational data, Robertson and Me- choso (2000) found that interannual changes in the intensity of the SACZ during austral summer are accompanied by SST anomalies over the southwest Atlantic. Here we show that this type of SST anomaly prescribed in the boundary conditions of our GCM does significantly influence the simulated SACZ and associated circulation and precipitation anomalies; the GCM's response exhibits the characteristics of a baroclinic response to thermal forcing. The influence, however, is of the opposite sense to the one observed: while an intensified SACZ has been found to be predominantly accompanied by cold SST anomalies around $10^{\circ}-30^{\circ} \mathrm{S}$ (Fig. 1), prescribing the latter in the GCM acts to damp the simulated SACZ and to extend it poleward.

In a second experiment, the leading EOF of South Atlantic SST was prescribed in the GCM, allowing for seasonal evolution. During austral summer, this EOF pattern (Fig. 4) is largely subtropical bears some similarity to the specifically SACZ-related pattern used in the first experiment; the main difference is that region 
a) UV-850

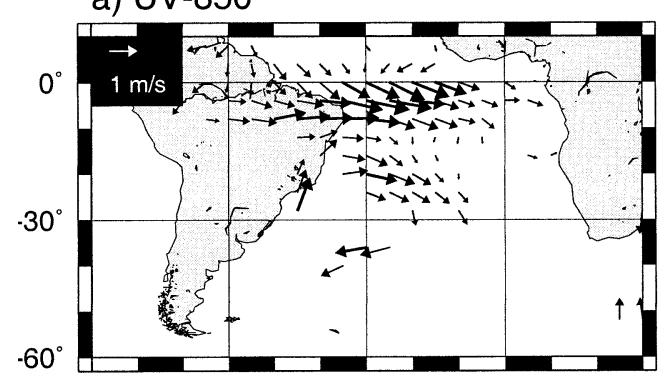

c) $\mathrm{T}-850$

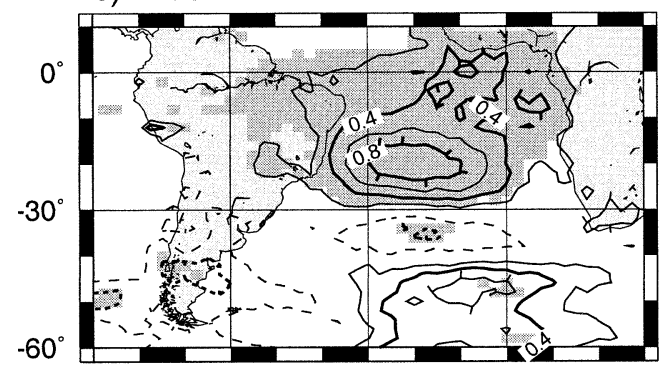

e) Net Sfc Heat Flux Up

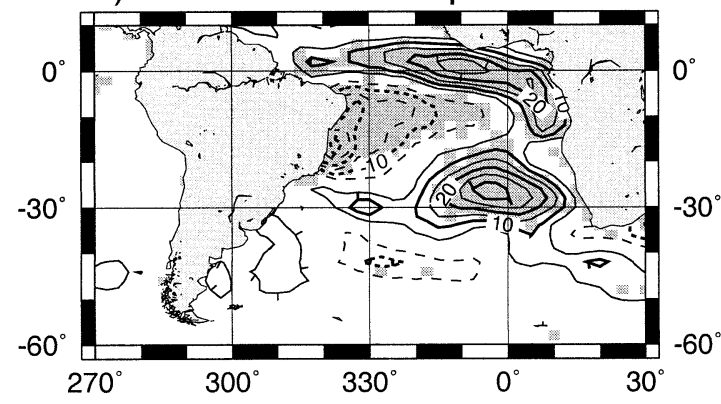

b) UV-200/OMG-500

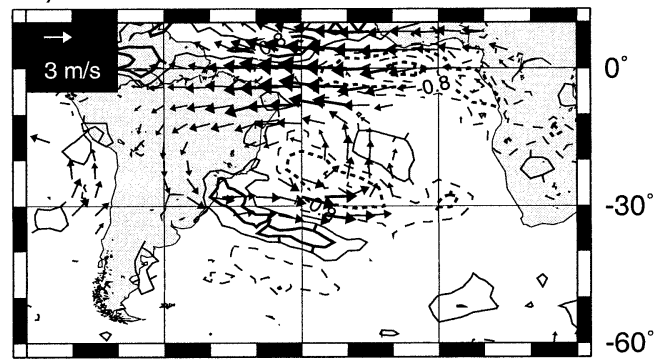

d) Precipitation

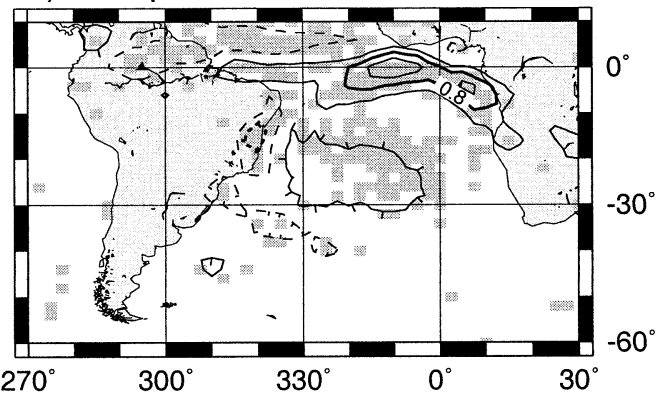

FIG. 5. JFM average GCM response to the SST anomaly evolution in Fig. 4. (a) $850-\mathrm{hPa}$ winds, (b) $200-\mathrm{hPa}$ winds and 500-hPa omega (contours), (c) $850-\mathrm{hPa}$ temperature, (d) precipitation, and (e) net surface heat flux into the atmosphere. The response is defined as the difference between an ensemble of 10 anomaly simulations and 10 control simulations. Shading indicates the $95 \%$ significance level, computed from a two-sided Student's $t$ test with 18 degrees of freedom, while in (a) and (b) only similarly significant vectors are plotted. Contour intervals are (b) $0.4 \times 10^{-2} \mathrm{~Pa} \mathrm{~s}^{-1}$, (c) $0.2 \mathrm{~K}$, (d) $0.4 \mathrm{~mm} \mathrm{day}^{-1}$, and (e) $5 \mathrm{~W} \mathrm{~m}^{-2}$; zero contours are omitted. Both (d) and (e) are spatially smoothed with a 9-point-average smoother. of anomalous meridional SST gradients is located farther eastward and that the opposite polarity was chosen. Allowing for these differences, the subtropical response is quite similar to that in the first experiment. However, a comparison with an observed regression (Fig. 7a) suggests that, unlike in the first experiment, the pattern does resemble atmospheric component of observed oceanatmosphere covariability over the subtropical South Atlantic.

Barreiro et al. (2002) have examined the response of the Community Climate Model (CCM3) GCM to observed Atlantic SST variations in an ensemble of multidecadal simulations. They find that the leading mode of SST-precipitation covariability in the simulation during austral summer consists of an SST pattern similar to the leading EOF, together with a baroclinic atmospheric response quite similar to our Fig. 5. Thus, the atmospheric response to subtropical SST anomalies over the South Atlantic does appear to be (i) fairly robust between models, and (ii) quite typical of observed covariability over the ocean.
Venegas et al. (1997) have studied the covariability between SST and sea level pressure (SLP) over the South Atlantic from the Comprehensive Ocean-Atmosphere Data Set (COADS). Their first mode of covariability (strongest in austral summer) consists of an SST distribution that is similar to that of our second experiment (Figs. 4b,c). The mode's covarying distribution of SLP anomalies reflects changes in strength of the subtropical anticyclone, such that a weakened anticyclone accompanies warmer subtropical SSTs. This is a similar atmospheric configuration to that shown in our observed regression map (Fig. 7a), and we have argued that it is at least partly oceanically forced [from our second experiment as well as Barreiro's (2002)]. Our argument is not necessarily incompatible with Venegas et al.'s (1997) conclusion from lagged regressions that the first mode of SST covariability is essentially associated with the atmosphere forcing the ocean. In the extratropics, Barsugli and Battisti (1998) have argued that while SST anomalies may predominantly reflect atmospheric forcing, positive feedback occurs because 
a) UV-850

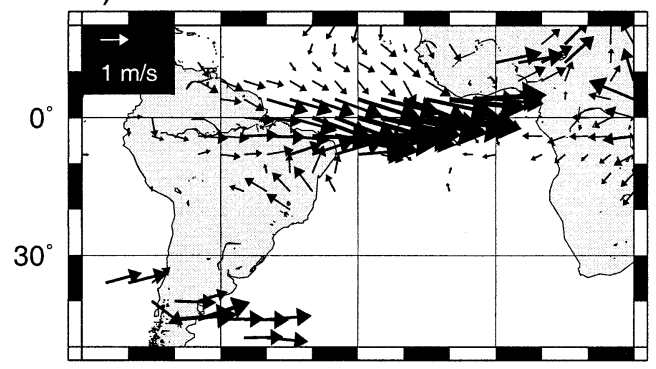

c) $\mathrm{T}-850$

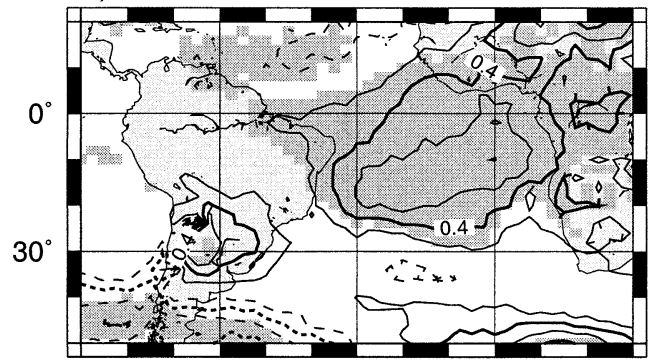

e) Net Sfc Heat Flux Up

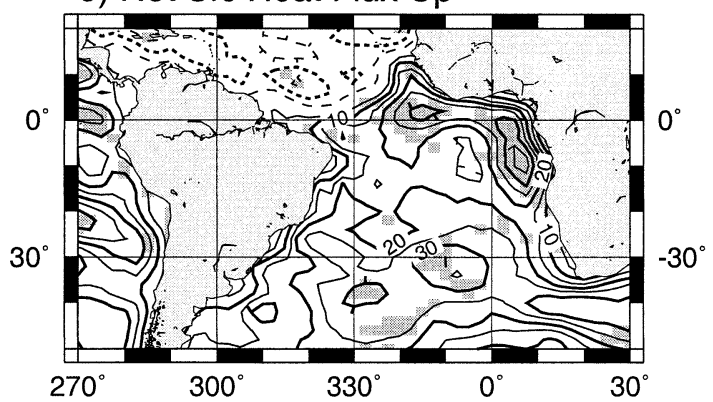

b) UV-200/OMG-500

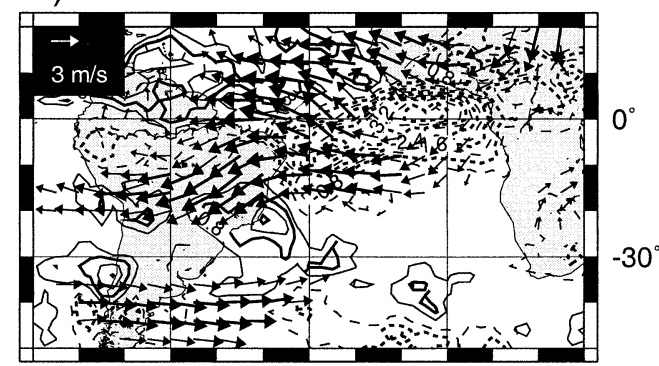

d) Precipitation

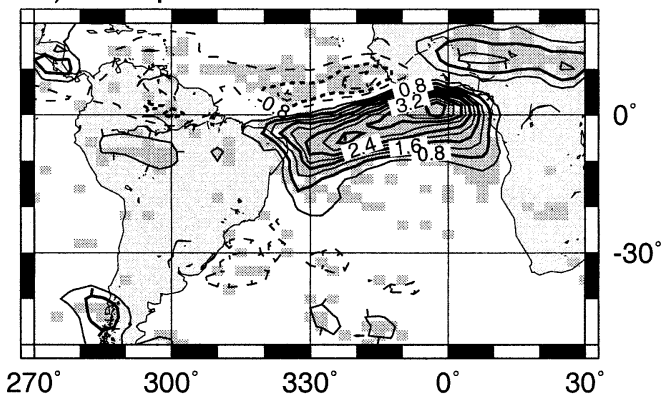

FIG. 6. AMJ average GCM response to the SST anomaly evolution in Fig. 4. Details as in Fig. 5. of a reduction in the thermal damping as the SST equilibrates toward the air temperature. Over the subtropical South Atlantic, the GCMs exhibit deep baroclinic responses that are more closely related to the tropical response to anomalous SST, suggesting a dynamical positive feedback. In the second experiment, the enhanced meridional thermal gradient at $30^{\circ} \mathrm{S}$ appears to set up a local thermally direct anomalous circulation that may act to intensify the gradient (Fig. 5), although longer simulations are required to confirm this result and analyze it in detail.

Both our experiments yield reasonably consistent results in the subtropics, with only the second producing a GCM response that resembles the observed covarying circulation pattern at low levels. This suggests that the SACZ variability is influenced more strongly by the basin-scale SST variability than by that in the underlying ocean. Taken together, our results indicate that the atmosphere over the subtropical South Atlantic is sensitive to SST anomalies. In addition, they indicate that the interannual mode of SACZ variability isolated by Robertson and Mechoso (2000) is largely an intrinsic mode of the atmosphere whose variability is predominantly independent of the underlying SST. While we cannot definitively conclude that the observed atmospheric anomalies in Fig. 1a are not caused by the underlying SST anomalies, the consistency of our GCM responses between the two experiments and their similarity with the results of Barreiro et al. (2002) makes a strong case. Unlike the baroclinic responses found here, Robertson and Mechoso's (2000) mode has the equivalent-barotropic structure of an extratropical Rossby wave. Kalnay et al. (1986) had already documented the latter in a particular case and argued that it be excited opportunistically by tropical heating and by wave dispersion from the Pacific, and damped by the local SST response to it. Remote forcing may take place on submonthly timescales through synoptic-scale waves (Liebmann et al. 1999), 40-60-day tropical intraseasonal oscillations (Nogués-Paegle and Mo 1997; Paegle et al. 2000), and is also seen during ENSO episodes (Barreiro et al. 2002; Cazes-Boezio et al. 2003). It has also been suggested that the North Atlantic Oscillation can influ- 

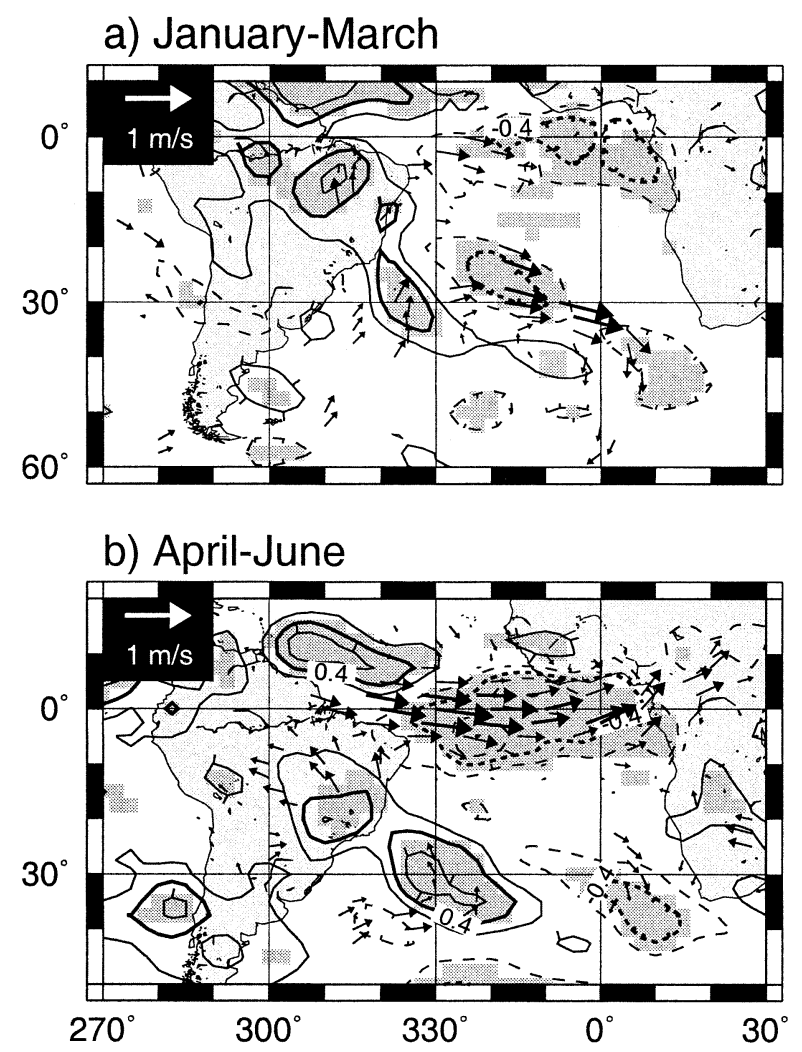

FIG. 7. Regression maps of NCEP-NCAR reanalysis $850-\mathrm{hPa}$ winds (vectors) and 500-hPa omega (contours) with leading monthly PC of South Atlantic SST 1950-99. (a) JFM average, and (b) AMJ average. Only statistically significant vectors are plotted and shading denotes significant omega values; the $95 \%$ significance level corresponds to a correlation value of 0.28 , which assumes 40 degrees of freedom. The contour interval is $0.2 \times 10^{-2} \mathrm{~Pa} \mathrm{~s}^{-1}$.

ence the rainfall over SE South America (Robertson and Mechoso 1998).

Notwithstanding the importance of remote influences on the SACZ, the strength and position of the subtropical anticyclone is an important factor and our GCM results as well as those of Barreiro et al. (2002), suggest that both can be influenced by South Atlantic SST anomalies. Figure 9 shows lag-correlation maps of Reynolds SST, constructed from the observed interannual PC used in Fig. 1. There is a clear indication that SST anomalies off the Brazilian coast tend to lag the SACZ, such that SST anomalies generated by the SACZ during austral summer (JFM) may persist into austral fall (AMJ) when they have the potential to influence the climate of SE South America (Diaz et al. 1998). Figures 9b and 9c suggest that there may also be a link with the Pacific off the coast of Chile, not seen contemporaneously in the GISST dataset.

The continuation of the second experiment into the boreal summer shows a very strong baroclinic equatorial response, with a near-zonal band of rainfall anomalies over the equatorial Atlantic. Rainfall anomalies are largely confined to oceanic areas with compensating dry regions over the tropical North Atlantic and Indian Ocean. The only noticeable anomaly over land is over sub-Saharan Africa; it is most pronounced during June, and could be interpreted as an early onset of the wet season there. It is somewhat surprising that the precipitation anomalies do not extend more into the continents although the mean seasonal cycle of precipitation is simulated quite realistically. One potentially limiting factor in this regard is that the GCM does not include interactive land surface processes. Barreiro et al. (2002) report a similar finding in the CCM3 model. The remote extratropical response of the atmosphere to the equatorial Atlantic SST anomalies is strongest in May, and yields significant $200-\mathrm{hPa}$ wind anomalies extending from southern South America to Europe in the AMJ seasonal mean; there is considerable interhemispheric asymmetry, in contrast to the rather symmetric extratropical response to El Niño during boreal winter. The interannual standard deviation of the observed zonal wind at $200 \mathrm{hPa}$ over Europe is $<4 \mathrm{~m} \mathrm{~s}^{-1}$ (computed from the NCEP-NCAR reanalysis data 1958-2001). The zonal component in the response composite in Fig. 8 is about $4 \mathrm{~m} \mathrm{~s}^{-1}$ over Europe, indicating the latter to be relatively strong (the amplitude of the prescribed SST anomaly corresponds to a two standard deviation observed interannual anomaly).

The dominant seasonal variation in SST anomalies over the South Atlantic appears as a "migration" between the subtropics in austral summer and the equatorial cold tongue complex in austral fall (Figs. 3 and 4). Anomalies of SST over the two regions are of similar amplitude and are highly correlated as shown in Fig. 10, which shows 12-month running averages of SST averaged over an equatorial and subtropical box. For individual months, the correlation is highest in March (0.66) and lowest in July (0.36). The correlation coefficient between the PCs of the EOFs of SST for JFM and AMJ shown in Fig. 3 is 0.67. Also plotted in Fig. 10 is an index of the strength of the subtropical anticyclone, whose strength clearly varies in opposition to SST through its association with the trade winds that affect SST in both regions. The simplest explanation is that the anticyclone influences SSTs in both regions, with seasonal variations in mixed-layer depth being an important factor: the shallow (austral) summer mixed layer over the subtropics would tend to give larger anomalies there in JFM, while the thermocline shallows in the eastern equatorial Atlantic in boreal summer. In addition, we have not been able to identify any statistical lag-lead relationship that would indicate a true migration. The results of our second GCM experiment suggest that the atmospheric response to both tropical and subtropical SST anomalies may be important, since the responses appear to be linked at upper levels.

Acknowledgments. We are grateful to Ping Chang and Marcelo Barreiro for useful discussions. The manuscript was substantially improved through the comments of 
a) UV-200 \& PSI-200

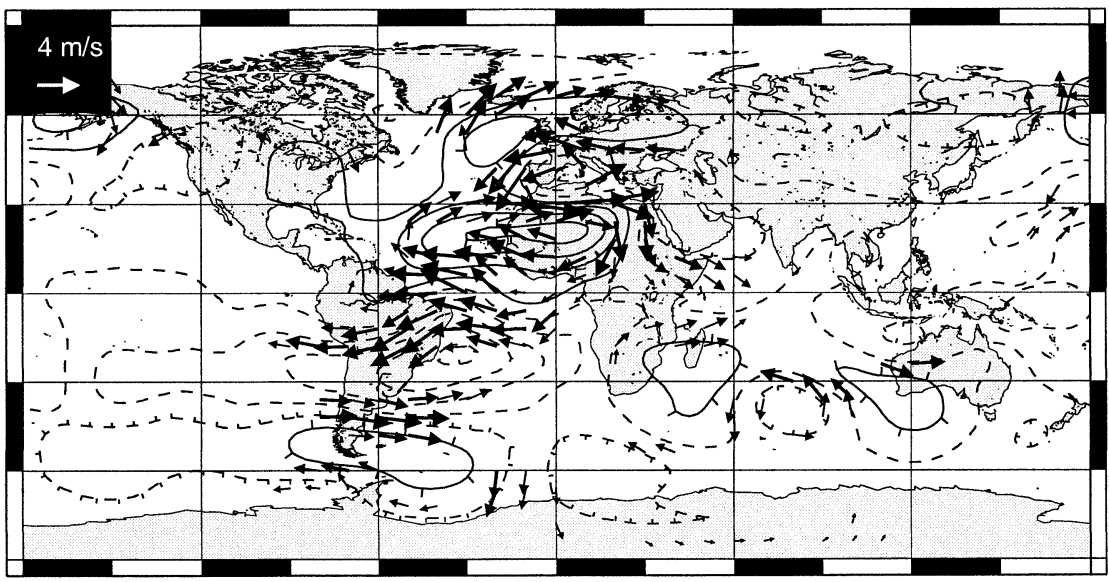

b) Precipitation

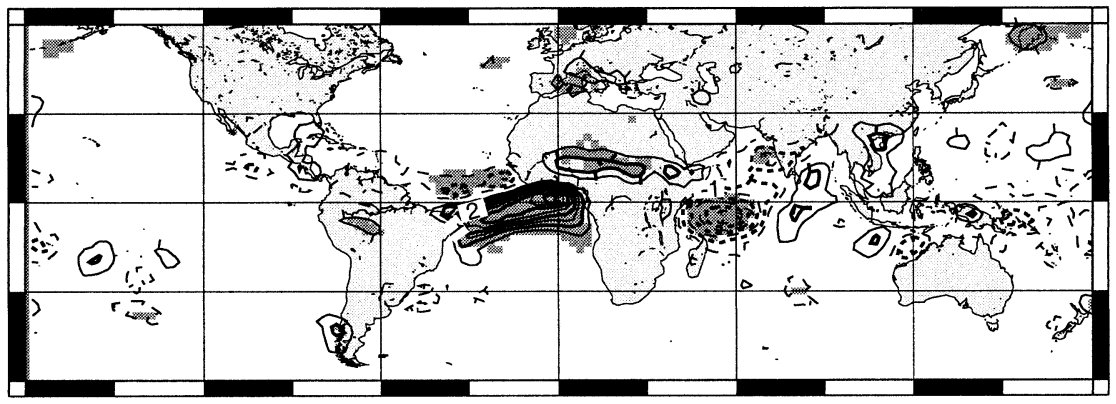

FIG. 8. Global AMJ response to the SST anomaly evolution in Fig. 4. (a) 200-hPa winds and streamfunction (contour interval $1.5 \times 10^{-6} \mathrm{~m}^{2} \mathrm{~s}^{-1}$, zero contour included), (b) precipitation (contour interval $0.5 \mathrm{~mm}$ day $^{-1}$, zero contour omitted). Other details as in Fig. 6.

a) October-December

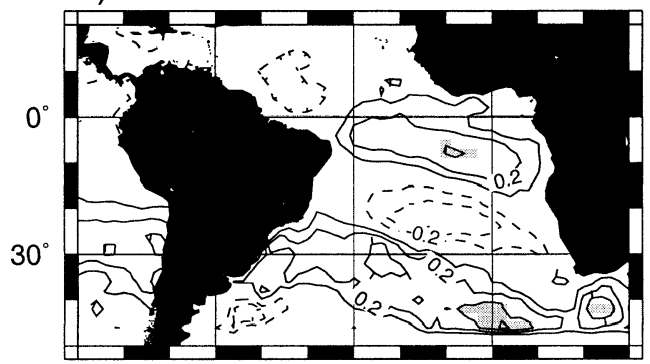

c) April-June

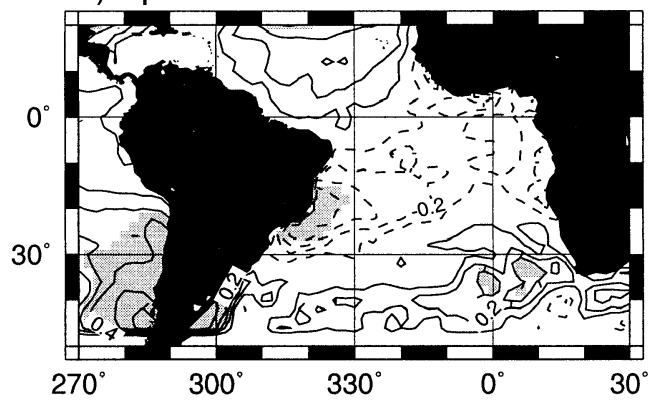

b) January-March

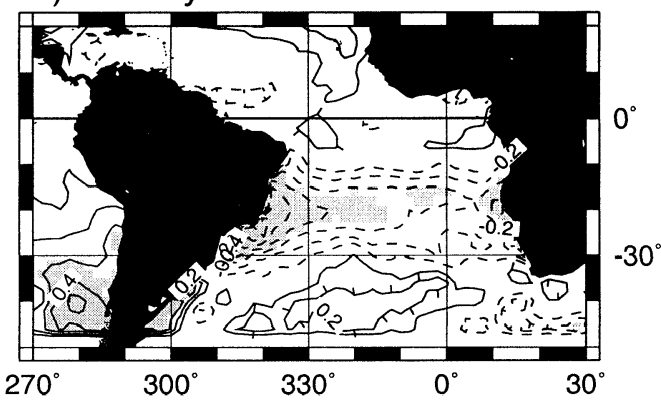

FIG. 9. Correlation maps of seasonal mean Reynolds SST with the JFM PC used to construct Fig. 1. (a) Preceding Oct-Feb, (b) contemporaneous JFM, and (c) the following AMJ. Locally 95\% significant areas are shaded, as in Fig. 1. Contour interval is 0.1 , with zero contour omitted. 


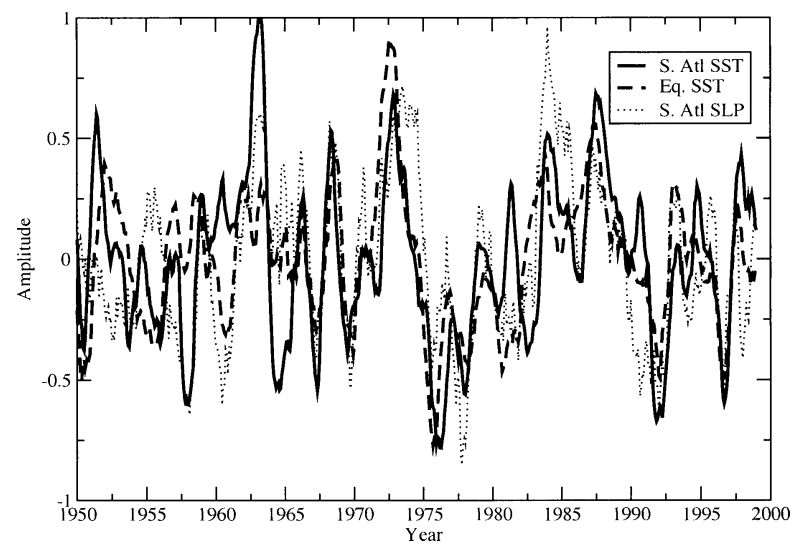

FIG. 10. Twelve-month running average anomaly time series of (a) subtropical South Atlantic SST $\left(14^{\circ}-26^{\circ} \mathrm{S}, 20^{\circ} \mathrm{W}-0^{\circ}\right.$; solid line), (b) equatorial SST $\left(2^{\circ} \mathrm{N}-4^{\circ} \mathrm{S}, 10^{\circ} \mathrm{W}-0^{\circ}\right.$; dashed line), and (c) normalized SLP $\left(15^{\circ}-45^{\circ} \mathrm{S}, 30^{\circ} \mathrm{W}-0^{\circ}\right.$; thin dotted line $)$ multiplied by -1 . The units of SST are K.

three anonymous reviewers. This work was supported primarily by NOAA Grant NA06GPO427 under the CLIVAR-Atlantic Program, and by NOAA under Grant NA06GP0511. The NCEP-NCAR reanalysis data were provided through the NOAA Climate Diagnostics Center (http://www.cdc.noaa.gov/).

\section{REFERENCES}

Arakawa, A., and W. H. Schubert, 1974: Interaction of a cumulus ensemble with the large-scale environment. Part I. J. Atmos. Sci., 31, 674-701.

Barreiro, M., P. Chang, and R. Saravanan, 2002: Variability of the South Atlantic convergence zone simulated by an atmospheric general circulation model. J. Climate, 15, 745-763.

Barros, V., M. Gonzalez, B. Liebmann, and I. Camilloni, 2000: Influence of the South Atlantic convergence zone and South Atlantic sea surface temperature on interannual summer rainfall variability in southeastern South America. Theor. Appl. Climatol., 67, 123-133.

Barsugli, J. J., and D. S. Battisti, 1998: The basic effects of atmosphere-ocean thermal coupling on midlatitude variability. J. Atmos. Sci., 55, 477-493.

Cazes-Boezio, G., A. W. Robertson, and C. R. Mechoso, 2003: Seasonal dependence of ENSO teleconnections over South America and relationships with precipitation in Uruguay. J. Climate, 16, 1159-1176.

Chang, P., L. Ji, and H. Li, 1997: A decadal climate variation in the tropical Atlantic ocean from thermodynamic air-sea interactions. Nature, 385, 516-518.

__ R. Saravanan, L. Ji, and G. C. Hegerl, 2000: The effect of local sea surface temperatures on atmospheric circulation over the tropical Atlantic sector. J. Climate, 13, 2195-2216.

Davis, R. E., 1976: Predictability of sea surface temperature and sea level pressure anomalies over the North Pacific Ocean. J. Phys. Oceanogr., 6, 249-266.

Diaz, A. F., C. D. Studzinski, and C. R. Mechoso, 1998: Relationships between precipitation anomalies in Uruguay and Southern Brazil and sea surface temperatures in the Pacific and Atlantic Oceans. J. Climate, 11, 251-271.

Dommenget, D., and M. Latif, 2000: Interannual to decadal variability in the tropical Atlantic. J. Climate, 13, 777-792.

Enfield, D. B., and D. A. Mayer, 1997: Tropical Atlantic sea surface temperature variability and its relation to El Niño-Southern Oscillation. J. Geophys. Res., 102, 929-945.

Farrara, J. D., C. R. Mechoso, and A. W. Robertson, 2000: Ensembles of AGCM two-tier predictions and simulations of the circulation anomalies during winter 1997-98. Mon. Wea. Rev., 128, 35893604.

Gandu, A. W., and P. L. Silva Dias, 1998: Impact of tropical heat sources on the South American tropospheric upper circulation and subsidence. J. Geophys. Res., 103, 6001-6015.

Harshvardhan, R. Davies, D. A. Randall, and T. G. Corsetti, 1987: A fast radiation parameterization for atmospheric circulation models. J. Geophys. Res., 92, 1009-1016.

— , D. A. Randall, T. G. Corsetti, and D. A. Dazlich, 1989: Earth radiation budget and cloudiness simulations with a general circulation model. J. Atmos. Sci., 46, 1922-1942.

Horel, J. D., A. N. Hahnmann, and J. E. Geisler, 1989: An investigation of the annual cycle of the convective activity over the tropical Americas. J. Climate, 2, 1388-1403.

Kalnay, E., K. C. Mo, and J. Paegle, 1986: Large-amplitude, shortscale stationary Rossby waves in the Southern Hemisphere: $\mathrm{Ob}$ servations and mechanistic experiments to determine their origin. J. Atmos. Sci., 43, 252-275.

— Project. Bull. Amer. Meteor. Soc., 77, 437-471.

Kodama, Y.-M., 1992: Large-scale common features of subtropical precipitation zones (the Baiu frontal zone, the SPCZ, the SACZ). Part I: Characteristics of subtropical frontal zones. J. Meteor. Soc. Japan, 70, 813-835.

_ 1993: Large-scale common features of subtropical precipitation zones (the Baiu frontal zone, the SPCZ, the SACZ). Part II: Conditions of the circulations for generating the STCZs. J. Meteor. Soc. Japan, 71, 581-610.

Li, J.-L., A. Arakawa, and C. R. Mechoso, 1999: Improved simulation of PBL moist processes with the UCLA GCM. Preprints, Seventh Conf. on Climate Variations, Long Beach, CA, Amer. Meteor. Soc., 35-40.

Liebmann, B., G. N. Kiladis, J. A. Marengo, T. Ambrizzi, and J. D. Glick, 1999: Submonthly convective variability over South America and the South Atlantic convergence zone. J. Climate, 12, 1877-1891.

Mechoso, C. R., J.-Y. Yu, and A. Arakawa, 2000: A coupled GCM pilgrimage: From climate catastrophe to ENSO simulations. General Circulation Model Development: Past, Present and Future: Proceedings of a Symposium in Honor of Professor Akio Arakawa, D. A. Randall, Ed., Academic Press, 539-575.

Namias, J., 1972: Influence of Northern Hemisphere general circulation on drought in northeastern Brazil. Tellus, 24, 336-342.

Nogués-Paegle, J., and K. C. Mo, 1997: Alternating wet and dry conditions over South America during summer. Mon. Wea. Rev., 125, 279-291.

Paegle, J. N., L. A. Byerle, and K. C. Mo, 2000: Intraseasonal modulation of South American summer precipitation. Mon. Wea. Rev., 128, 837-850.

Randall, D. A., and D. M. Pan, 1993: Implementation of the ArakawaSchubert cumulus parameterization with a prognostic closure. The Representation of Cumulus Convection in Numerical Models of the Atmosphere, K. A. Emanuel and D. J. Raymond, Eds., Amer. Meteor. Soc., 137-144.

Rayner, N. A., C. K. Folland, D. E. Parker, and E. B. Horton, 1995: A new global sea-ice and sea surface temperature (GISST) data set for 1903-1994 for forcing climate models. Hadley Centre Internal Note 69, $13 \mathrm{pp}$.

Reynolds, R. W., and T. M. Smith, 1994: Improved global sea surface temperature analyses using optimum interpolation. J. Climate, 7, 929-948.

Robertson, A. W., and C. R. Mechoso, 1998: Interannual and decadal cycles in river flows of southeastern South America. J. Climate, 11, 2570-2581. 
- and - 2000: Interannual and interdecadal variability of the South Atlantic convergence zone. Mon. Wea. Rev., 128, 29472957.

Saravanan, R., and P. Chang, 2000: Interactions between tropical Atlantic variability and El Niño-Southern Oscillation. J. Climate, 13, 2177-2194.

Suarez, M. J., A. Arakawa, and D. A. Randall, 1983: The parameterization of the planetary boundary layer in the UCLA general circulation model: Formulation and results. Mon. Wea. Rev., 111, 2224-2243.
Tseng, L., and C. R. Mechoso, 2000: A quasi-biennial oscillation in the equatorial Atlantic Ocean. Geophys. Res. Lett., 28, 187-190.

Venegas, S. A., L. A. Mysak, and D. N. Straub, 1997: Atmosphereocean coupled variability in the South Atlantic. J. Climate, 10, 2904-2920.

Virji, H., 1981: A preliminary study of summertime tropospheric circulation patterns over South America estimated from cloud winds. Mon. Wea. Rev., 109, 596-610.

Zebiak, S. E., 1993: Air-sea interaction in the equatorial Atlantic region. J. Climate, $6,1567-1586$. 